\title{
DESENVOLVIMENTO DE TECNOLOGIA PARA CONFECÇÃO DE ELETRODOS E CONJUNTOS ELETRODO- MEMBRANA-ELETRODO (MEA) POR IMPRESSÃO À TELA PARA APLICAÇÃO EM MÓDULOS DE POTÊNCIA DE CÉLULAS PEMFC
}

\author{
Valéria Cristina Fernandes*, Edgar Ferrari da Cunha, Rafael Nogueira Bonifácio, Mauro André Dresch, Gustavo Doubek, \\ Elisabete Inacio Santiago e Marcelo Linardi \\ Instituto de Pesquisas Energéticas e Nucleares, Av. Prof. Lineu Prestes, 2242, Cidade Universitária, 05508-000 São Paulo - SP, Brasil
}

Recebido em 12/8/11; aceito em 4/10/11; publicado na web em 20/1/12

\begin{abstract}
DEVELOPMENT OF TECHNOLOGY FOR PRODUCING ELECTRODES AND MEMBRANE ELECTRODE ASSEMBLIES (MEAs) BY SIEVE PRINTING METHOD FOR USE IN HIGH POWER PEMFC STACKS. Significant functions in the Proton Exchange Membrane Fuel Cells (PEMFCs) rely on Gas Diffusion Layers (GDLs), such as control the water balance in the membrane electrode assembly (MEA), allow suitable gas permeability and porosity, etc. Aware of the GDL importance in the cell performance and its great demand in scale-up projects, the fuel cell research group at Instituto de Pesquisas Energéticas e Nucleares (IPEN) has developed a Sieve Printing method (innovative in Brazil) as a strategic solution for producing GDL and electrodes used in high power PEMFC stacks. The method has shown to be adequate to fabricate low cost electrodes, GDLs of different dimensions and to produce any amount of MEAs for power stacks.
\end{abstract}

Keywords: membrane electrode assembly (MEA); PEMFC; sieve printing method.

\section{INTRODUÇÃO}

Atualmente, uma das alternativas limpas e eficientes mais promissoras para aplicação como fonte de energia elétrica em sistemas distribuídos são as células a combustível, particularmente aquelas alimentadas por hidrogênio/ar.

Células a combustíveis são dispositivos conversores de energia química em energia elétrica e térmica de forma direta, gerando potência por meio do suprimento externo e constante de um combustível e um oxidante. Dentre os principais tipos de células a combustível, as células PEMFC (Proton Exchange Membrane Fuel Cell) têm características versáteis, apresentando-se viáveis, tanto para geração estacionária, quanto em aplicações portáteis e automotivas. ${ }^{1-4}$ Além disso, apresentam vantagens importantes como alta eficiência, com baixa ou nenhuma emissão de poluentes. Atualmente, o fator mais determinante para a sua entrada no mercado, apesar do grande número de pesquisas, é ainda o seu custo. ${ }^{5,6}$ Para um melhor desenvolvimento da tecnologia deste novo dispositivo energético, faz-se necessário o aprimoramento de cada componente presente nesse tipo de célula. A Figura 1 representa um esquema simplificado da célula a combustível do tipo PEMFC.

O funcionamento de células PEMFC ocorre a partir da alimentação externa e contínua de um combustível $\left(\mathrm{H}_{2}\right)$ e um oxidante $\left(\mathrm{O}_{2}\right)$. No ânodo, ocorre a reação de oxidação do hidrogênio a prótons e elétrons. Os elétrons são transportados por um circuito externo em direção ao cátodo e os prótons são transportados até o cátodo através do eletrólito. No cátodo ocorre a reação de redução do oxigênio, com o envolvimento dos prótons e elétrons provenientes do ânodo, gerando água e calor. Ambas as reações, oxidação do hidrogênio (ROH) e redução do oxigênio (RRO), ocorrem na interface eletrodo/ eletrólito, ${ }^{3}$ cuja reação eletroquímica global de formação da água apresenta potencial reversível de $1,23 \mathrm{~V} \mathrm{VS}$. ENH, a $25^{\circ} \mathrm{C}$. As reações parciais e a reação global para hidrogênio e oxigênio são indicadas nas Equações 1, 2 e $3 .^{3}$

*e-mail: val_crisfer@yahoo.com.br

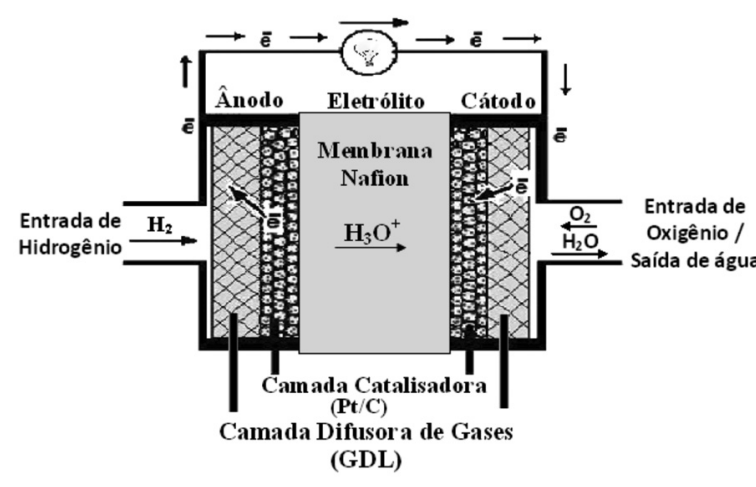

Figura 1. Esquema simplificado de um sistema de célula a combustível do tipo PEMFC

$$
\begin{gathered}
\text { Ânodo: } \mathrm{H}_{2} \rightarrow 2 \mathrm{H}^{+}+2 \mathrm{e}^{-} \\
\text {Cátodo: } 1 / 2 \mathrm{O}_{2}+2 \mathrm{H}^{+}+2 \mathrm{e}^{-} \rightarrow \mathrm{H}_{2} \mathrm{O} \\
\text { Reação global: } \mathrm{H}_{2}+1 / 2 \mathrm{O}_{2} \rightarrow \mathrm{H}_{2} \mathrm{O}
\end{gathered}
$$

Como observado na Figura 1, o principal constituinte da célula é o conjunto eletrodo-membrana-eletrodo (MEA - Membrane Electrodes Assembly). Em sua forma mais simples o MEA apresenta três componentes: uma membrana trocadora de prótons (eletrólito da célula) e dois eletrodos (ânodo e cátodo), chamados de eletrodos de difusão de gás (EDG) (Figura 1S, material suplementar). Entretanto, a tecnologia existente na fabricação do MEA envolve muitos aspectos que vão além do simples empilhamento dessas camadas, já que qualquer modificação estrutural, física ou química, em uma dessas partes afeta diretamente as características do conjunto e, por consequência, o desempenho geral da célula.

A membrana trocadora de prótons (membrana polimérica) atua como eletrólito nas células PEMFCs sendo, pois, responsável pelo transporte dos prótons do ânodo ao cátodo, além de atuar como uma barreira física, evitando o contato direto entre o $\mathrm{H}_{2}$ e o $\mathrm{O}_{2}$ e, por consequência, o consumo não faradáico dos gases reagentes. ${ }^{3,7,8}$ Dentre os eletrólitos trocadores de prótons disponíveis, as membranas Nafion 
são as mais utilizadas e se destacam por oferecer alta estabilidade química e mecânica e alta condutividade protônica, quando hidratadas.

Os EDG (ânodo e cátodo) ${ }^{4}$ são formados por duas camadas porosas: uma camada difusora de gases $(\mathrm{GDL})^{9,10}$ e uma camada catalisadora. A camada difusora tem características hidrofóbicas e situa-se mais perto dos canais de distribuição de gases. Esta camada tem a função de permitir a permeação dos gases reagentes (hidrogênio e oxigênio) através de sua estrutura, distribuindo-os de modo uniforme até a camada catalisadora. Devido à baixa solubilidade dos gases reagentes, para o bom funcionamento das células a combustível é indispensável o uso de difusores de gás (GDL) com elevada área superficial. O desenvolvimento desses GDLs, em particular do eletrodo catódico, é de extremo interesse visto que também apresenta aplicações em baterias de metal/ar e na indústria de cloro/soda. ${ }^{11}$ Além disso, o GDL também tem a função de conduzir eficientemente os elétrons participantes do processo global. ${ }^{9}$

A camada catalisadora promove a reação eletroquímica e por esse motivo a área eletroquimicamente ativa que essa camada apresenta é um dos fatores que influenciam, definitivamente, na eficiência da célula. Essa camada é formada, em geral, por platina (Pt) nanoestruturada suportada em carbono $(\mathrm{Pt} / \mathrm{C})$ de alta área superficial. Além disso, a utilização do próprio material da membrana (Nafion) na composição do eletrodo permite não só a redução da carga de Pt (eletrocatalisador) para um mesmo desempenho, mas também a maximização da interface eletrodo/eletrólito, diminuindo o sobrepotencial de ativação. ${ }^{3}$ A camada catalisadora pode ser aplicada diretamente sobre os GDLs ou sobre o eletrólito polimérico (membrana Nafion), de acordo com o método de produção adotado, e essa diferença de metodologia de preparo pode conferir diferentes desempenhos aos MEAs resultantes.

$\mathrm{O}$ aumento de escala e a produção de MEAs para uso comercial são ainda desafios no Brasil e objetos de estudo do Centro de Células a Combustível e Hidrogênio do Instituto de Pesquisas Energéticas e Nucleares (CCCH-IPEN). O CCCH atua desde 2000 com pesquisa e desenvolvimento dos principais componentes de uma célula a combustível do tipo PEMFC, tais como, materiais de eletrodo, membranas e MEAs.

Em 2008, Andrade $^{12}$ desenvolveu um processo inédito no Brasil de produção de MEAs, utilizando o método de impressão à tela (sieve printing). Nesse estudo, foram produzidos MEAs de áreas geométricas de 25 e $144 \mathrm{~cm}^{2}$. Os MEAs de $144 \mathrm{~cm}^{2}$ demonstraram bom desempenho, alcançando densidades de corrente acima de 300 $\mathrm{mA} \mathrm{cm} \mathrm{c}^{-2}$ a $0,6 \mathrm{~V}$, com carga de platina de $0,4 \mathrm{mg} \mathrm{Pt} \mathrm{cm}^{-2}$ tanto para o cátodo como para o ânodo, operando a célula com $\mathrm{H}_{2} / \mathrm{O}_{2}$. Em outro trabalho Andrade et al. ${ }^{13}$ realizaram um estudo comparativo entre o método recém-desenvolvido (impressão à tela) e o método de aspersão, já estabelecido anteriormente no grupo. Os resultados mostraram que eletrodos preparados utilizando o método de impressão à tela apresentam uma uniformidade geométrica maior em comparação ao método de aspersão, sem apresentar significativas mudanças na porosidade do eletrodo. Essa característica também refletiu em um melhor desempenho da célula. Comparando as curvas de polarização, MEAs de $25 \mathrm{~cm}^{2}$ de área geométrica obtidos pelo método de impressão à tela apresentaram valores de densidade de corrente e potência 39,8\% maiores do que os obtidos pelo método de aspersão para a célula no potencial de $0,6 \mathrm{~V}$ operando com $\mathrm{H}_{2} / \mathrm{O}_{2}$ com uma mesma carga de Pt.

Paralelamente a esse estudo, o grupo tem desenvolvido trabalhos na área de modelagem e simulação de células unitárias e stacks, obtendo êxito no desenvolvimento de placas de distribuição de gases (bipolares e end-plates), por meio de análises numéricas de diferentes configurações geométricas. ${ }^{14-16}$ Os resultados obtidos foram fundamentais para a produção das placas utilizadas no trabalho de Robalinho. ${ }^{17}$ A partir desse trabalho, o grupo adquiriu a competência para a modelagem de todos os processos envolvidos no funcionamento de uma célula PEMFC, integrando os fenômenos eletroquímicos ao desenvolvimento de placas de distribuição de gases. Estes resultados experimentais possibilitaram a validação do desenvolvimento numérico computacional de uma célula unitária com o MEA de 144 $\mathrm{cm}^{2}$, que apresentou uma densidade de corrente de $480 \mathrm{~mA} \mathrm{~cm}^{-2}$ a $0,6 \mathrm{~V}$ operando com $\mathrm{H}_{2} / \mathrm{O}_{2} \cdot{ }^{17}$ Este aparato laboratorial foi determinante para os testes de MEAs e de seus parâmetros e processos de obtenção, no IPEN.

A partir da experiência prévia adquirida pelo grupo, Cunha ${ }^{18}$ desenvolveu, juntamente com o apoio da indústria nacional, um protótipo de 500 We de potencia nominal de célula PEMFC. Neste trabalho foi realizado um estudo de scale-up de produção de MEAs, englobando toda a tecnologia desenvolvida nos laboratórios de células do IPEN como, por exemplo, a produção de pasta catalítica, aplicação da pasta em membranas pelo processo de impressão à tela e prensagem e montagem de MEAs, bem como o desenvolvimento de novas configurações de placas bipolares, incluindo novos materiais e vedações e procedimentos operacionais. Foi realizado um teste prolongado de $100 \mathrm{~h}$ de operação em uma célula unitária para verificação da estabilidade e confiabilidade dos componentes da célula. Os resultados foram bastante satisfatórios, não sendo verificada nenhuma alteração no desempenho global da célula no período estudado. ${ }^{18}$ Foi construído um módulo a partir do empilhamento em série de dez células unitárias e a potência de 500 We foi obtida a uma densidade de corrente de 590,3 $\mathrm{mA} \mathrm{cm}^{-2}$ no potencial de $0,6 \mathrm{~V}$ com eficiência de $40 \%$. Com estes resultados foi alcançado o objetivo institucional de construir um módulo com tecnologia $100 \%$ nacional.

Em 2010, Bonifácio ${ }^{19}$ aperfeiçoou o processo de produção de eletrodos por impressão à tela e também realizou um estudo importante no que se refere à formulação e produção de tinta catalítica (Tinta Precursora da Camada Catalisadora - TPCC) para ser aplicada em escala semi-industrial..$^{20,21} \mathrm{~A}$ tinta produzida apresentou alta estabilidade e menor toxicidade dos reagentes utilizados quando comparada com a tinta produzida anteriormente. ${ }^{12}$ Essa estabilidade proporcionou maior homogeneidade e facilidade de deposição e, por consequência, melhor controle da carga de eletrocatalisador depositada. Além disso, a TPCC apresentou comportamentos semelhantes à de tintas comercialmente utilizadas em processos de impressão à tela. Esse comportamento possibilitou reprodutibilidade e rapidez principalmente na produção de eletrodos de grandes áreas geométricas. ${ }^{19}$

Visando ainda o objetivo do aumento de escala e da produção de MEAs com alta eficiência e confiabilidade, o grupo de pesquisa do $\mathrm{CCCH}$ buscou também a otimização de algumas características presentes nos GDLs, como porosidade, grau de hidrofobicidade, gerenciamento de água e permeabilidade dos gases, objetivando maior desempenho do MEA. ${ }^{22}$ A porosidade do GDL, como descrito anteriormente, melhora a distribuição dos gases, maximizando o acesso destes aos sítios catalíticos, e o controle sobre a hidrofobicidade proporciona um gerenciamento adequado de água na interface eletrodo/eletrólito, impedindo assim o ressecamento das regiões de interface ao eletrodo anódico e o encharcamento nas regiões de interface do eletrodo catódico. ${ }^{23}$

Os materiais utilizados como GDLs também devem ser estáveis química e mecanicamente e serem capazes de manter uma alta condutividade elétrica por toda a vida útil da célula. Nesse sentido, GDLs confeccionados a partir de papel de carbono, apesar de apresentarem um bom desempenho no que se refere à porosidade e aos processos de gerenciamento de água, possuem uma vida útil limitada. Já os GDLs, que utilizam tecido de carbono como substrato, apresentam uma maior eficiência e vida útil para aplicação em módulos de potência. ${ }^{11,24-26}$

Atualmente, a indústria de células a combustível e grande parte dos centros de pesquisa utilizam GDLs constituídos por uma suspensão de carbono e PTFE que recobrem uma ou ambas as faces de 
um tecido de carbono condutor formando, dessa forma, um material compósito com elevada área superficial e grande hidrofobicidade. A face do GDL recoberta pela suspensão de carbono e PTFE pode receber posteriormente a aplicação da camada catalisadora, formando assim os eletrodos (ânodo ou cátodo), ou ficar sobreposta ao MEA, quando esta camada catalisadora é aplicada diretamente sobre o eletrólito (membrana Nafion).

\section{Objetivos}

Ciente da importância do GDL no desempenho da célula a combustível e de sua grande demanda em projetos de scaling-up, o grupo de pesquisa do $\mathrm{CCCH}$ focou-se na automação do processo de fabricação de GDLs a partir da deposição de uma emulsão carbonácea sobre o substrato de tecido de carbono. Esse trabalho teve como objetivo principal preparar GDLs e eletrodos de forma semiautomatizada, utilizando o método de impressão à tela para a produção de MEAs com grande área geométrica $\left(248 \mathrm{~cm}^{2}\right)$ para aplicação em módulos de potência pré-comerciais, com tecnologia $100 \%$ nacional.

\section{PARTE EXPERIMENTAL}

\section{Caracterização morfológica}

A análise morfológica da superfície e da seção transversal do MEA foi realizada com o auxílio de um microscópio eletrônico de varredura (MEV) Philips XL-30.

\section{Preparo da camada difusora utilizando o sistema semiautomatizado}

As camadas difusoras foram preparadas pela deposição de uma emulsão de carbono Vulcan XC-72R sobre um substrato de tecido de carbono utilizando o método de impressão à tela, descrito a seguir.

O tecido de carbono utilizado como substrato foi previamente tratado termicamente a $450{ }^{\circ} \mathrm{C}$ durante $1 \mathrm{~h}$ e, em seguida, imerso pelo mesmo intervalo de tempo em um banho contendo uma solução de $\mathrm{HNO}_{3} 25 \%$ a $80{ }^{\circ} \mathrm{C}$, com posterior banho em água ultrapura nas mesmas condições. Os procedimentos descritos acima foram realizados para eliminação de orgânicos e acidificação do substrato, respectivamente.

Após esses procedimentos, uma mistura composta de pó de carbono Vulcan XC-72R, Cabot, emulsão de Teflon (PTFE-TE-306A, DuPont) e solventes orgânicos foi preparada, formando uma emulsão hidrofóbica (camada carbonácea) que foi devidamente homogeneizada com o auxílio de um dispersor (Dispersor Extratur - QUIMIS). Essa emulsão foi então depositada sobre uma das faces do tecido de carbono (previamente tratado) por impressão à tela, utilizando uma máquina semiautomatizada de impressão (EKRA modelo E-1) (Figura 2Sa, material suplementar). A deposição da emulsão hidrofóbica foi realizada ajustando parâmetros como velocidade de deposição, trama da tela de impressão, consistência da emulsão. A massa depositada sobre o tecido de carbono foi de $3 \mathrm{mg} \mathrm{cm}^{-2}$.

Após a deposição da emulsão sobre o tecido de carbono, o material obtido foi tratado termicamente para a eliminação dos solventes, com consequente formação de poros e aderência entre o tecido de carbono e a emulsão hidrofóbica aplicada, formando assim uma camada difusora modificada.

\section{Preparo da camada catalisadora}

As camadas catalisadoras foram preparadas a partir da deposição de uma Tinta Precursora da Camada Catalítica (TPCC), conforme metodologia previamente desenvolvida pelo Centro de Células a Combustível do Instituto de Pesquisas Energéticas e Nucleares (CCCH-IPEN). ${ }^{20,21} \mathrm{~A}$ TPCC foi preparada a partir da mistura do catalisador de platina suportado em carbono (Pt/C - BASF), solução de Nafion e solventes orgânicos. Para o preparo da tinta em escala piloto, foi construído um reator químico composto de homogeneizador de alta velocidade, sistema de aquecimento e agitador mecânico com pás raspadoras, conforme pode ser observado na Figura $2 \mathrm{Sb}$, material suplementar. A TPCC foi então aplicada sobre os GDLs modificados (tecido de carbono + emulsão hidrofóbica) preparados previamente utilizando a mesma máquina de impressão empregada na produção das camadas difusoras. A carga total de Pt obtida para os eletrodos foi de 0,4 $\mathrm{mg} \mathrm{Pt} \mathrm{cm}^{-2}$ para ânodos e 0,6 $\mathrm{mg} \mathrm{Pt} \mathrm{cm}^{-2}$ para cátodos. Após a deposição da TPCC, os eletrodos foram secos em estufa para eliminar os solventes utilizados na produção da tinta. Para fins de comparação, a camada catalisadora também foi aplicada diretamente sobre um tecido de carbono teflonado (EC-CC1-060T, ElectroChem Inc.), formando eletrodos (cátodos e ânodos) que não apresentam em sua composição a emulsão hidrofóbica. Ambos os equipamentos, o reator de preparação da TPCC e máquina de impressão estão instalados no laboratório de confecção de MEAs do CCCH do IPEN.

\section{Montagem do conjunto membrana-eletrodos e teste em célula unitária}

Todos os conjuntos membrana-eletrodos de área geométrica de $248 \mathrm{~cm}^{2}$ foram preparados por prensagem a quente na temperaturade $125^{\circ} \mathrm{C}$ e 8 toneladas durante $8 \mathrm{~min}$, utilizando membranas Nafion 115 (forma $\mathrm{H}^{+}$, DuPont) como eletrólito. Os conjuntos foram acondicionados em uma célula unitária fornecida pela empresa nacional Electrocell. A célula unitária foi monitorada em uma estação de trabalho que permitiu o controle da temperatura via câmaras de umidificação e fluxo de massa dos gases reagentes, além do controle de corrente e potencial. A pressão de operação utilizada em todos os experimentos foi a atmosférica. Foram obtidas galvanostaticamente curvas de polarização em estado estacionário, utilizando-se oxigênio ou ar saturado com água ultrapura como oxidante no cátodo e hidrogênio saturado com água ultrapura no ânodo. Para as medidas realizadas em oxigênio utilizaram-se as temperaturas de 90 e $80{ }^{\circ} \mathrm{C}$ nos umidificadores e fluxos de 1,18 e $0,9 \mathrm{~L} \mathrm{~min}^{-1}$ para ânodo e cátodo, respectivamente. Os experimentos utilizando ar como oxidante foram realizados para os MEAs preparados na ausência e na presença da emulsão hidrofóbica em diferentes condições de operação. As condições de operação otimizadas podem ser visualizadas na Tabela 1 .

Tabela 1. Condições otimizadas de operação para os experimentos utilizando ar como gás oxidante

\begin{tabular}{lcc}
\hline Eletrodos & $\begin{array}{c}\text { Ânodo } \\
\text { temperatura/ } \\
\text { fluxo de gás }\end{array}$ & $\begin{array}{c}\text { Cátodo } \\
\text { temperatura/ } \\
\text { fluxo de gás }\end{array}$ \\
\hline $\begin{array}{l}\text { com emulsão } \\
\text { hidrofóbica (eletrodo 1) }\end{array}$ & $65^{\circ} \mathrm{C} / 1,22 \mathrm{~L} \mathrm{~min}^{-1}$ & $60{ }^{\circ} \mathrm{C} / 7,00 \mathrm{~L} \mathrm{~min}^{-1}$ \\
$\begin{array}{l}\text { sem emulsão } \\
\text { hidrofóbica (eletrodo 2) }\end{array}$ & $90^{\circ} \mathrm{C} / 1,22 \mathrm{~L} \mathrm{~min}^{-1}$ & $80{ }^{\circ} \mathrm{C} / 6,10 \mathrm{~L} \mathrm{~min}^{-1}$ \\
\hline
\end{tabular}

Todas as condições de operação foram avaliadas e otimizadas segundo experiência prévia do grupo, com a finalidade de obter o melhor desempenho para cada um dos eletrodos. Anteriormente às medidas, o sistema foi acondicionado em $0,6 \mathrm{~V}$ durante $2 \mathrm{~h}$, tanto para as medidas com oxigênio como para as realizadas em ar com o objetivo de se alcançar a condição de estado estacionário. 


\section{RESULTADOS E DISCUSSÃO}

\section{Caracterização morfológica}

Na Figura 2a é apresentada uma micrografia da superfície do GDL produzido pelo método de impressão à tela. Verifica-se que a camada difusora apresenta uma superfície uniforme e homogênea em toda a área analisada. As trincas observadas na superfície são resultantes do processo de evaporação dos solventes utilizados no preparo da emulsão carbonácea. Também pode ser notada, nessa figura, a presença de formas geométricas repetidas e uniformemente distribuídas, em alto relevo na superfície. Tal resultado é uma consequência do método de produção, uma vez que as formas geométricas presentes correspondem à trama da tela utilizada para a impressão.

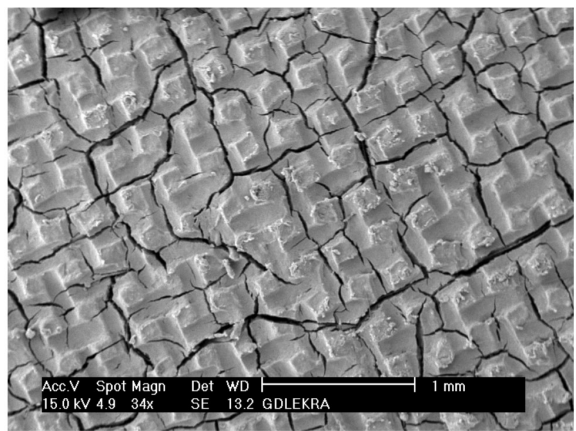

(a)

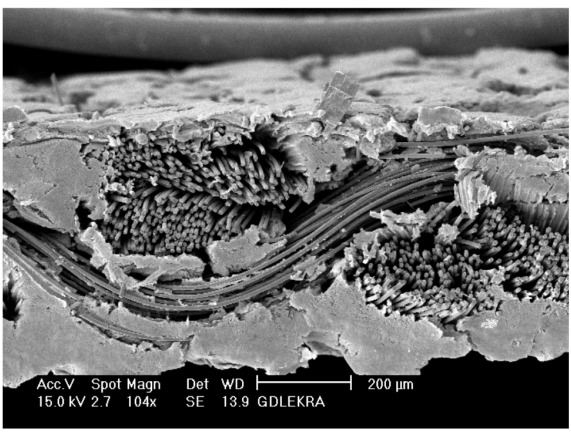

(b)

Figura 2. (a) Micrografias eletrônicas de varredura (MEV) da superfície e (b) do corte transversal de GDL produzidos pelo método de impressão à tela

Na Figura $2 b$ é mostrada uma micrografia da secção transversal do mesmo GDL. Observa-se a coexistência de duas regiões, no interior o tecido de carbono e, recobrindo-o, a emulsão carbonácea. Também pode ser observado que houve a impregnação da emulsão carbonácea ao interior da trama do tecido de carbono, porém em menor quantidade quando comparada ao exterior.

\section{Caracterização eletroquímica}

Na Figura 3a estão apresentados os resultados comparativos para as curvas de polarização e de densidade de potência obtidas em diferentes condições de operação da célula, utilizando ar como oxidante. Pode ser observado um aumento de $40 \%$ no desempenho da célula, quando se reduz a temperatura do sistema. Esse comportamento está relacionado diretamente com um melhor gerenciamento de água nos canais de difusão.

Na Figura 3b estão apresentadas as curvas de polarização e de densidade de potência obtidas para a operação da célula, utilizando oxigênio ou ar como oxidante. A célula alimentada com $\mathrm{H}_{2} / \mathrm{O}_{2}$ apresenta
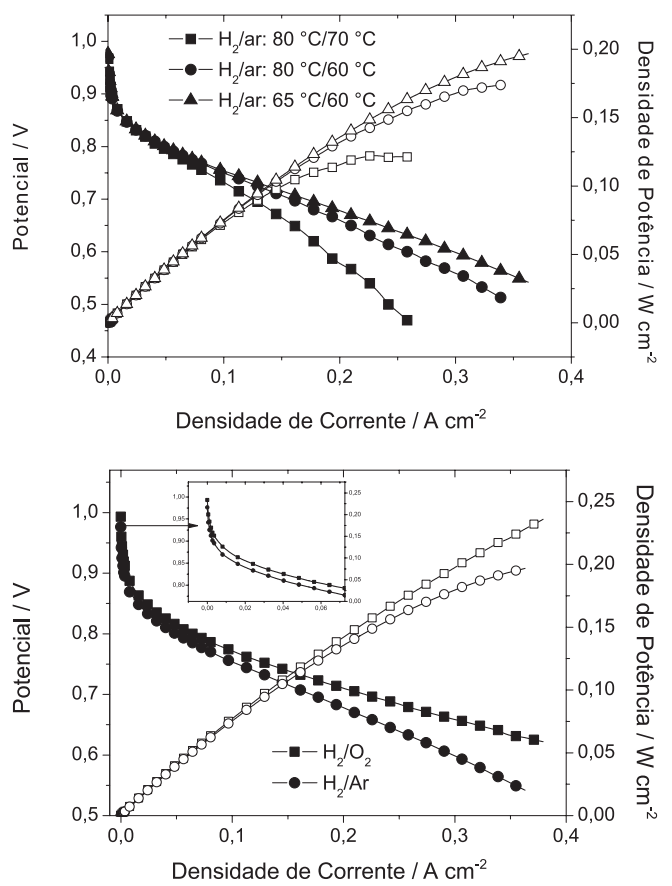

Figura 3. (a) Curvas de polarização e potência para o MEA de área geométrica de $248 \mathrm{~cm}^{2}$ confeccionado utilizando os GDLs produzidos pelo método de impressão à tela, em diferentes temperaturas de operação. (b) Curvas de polarização e de densidade de potência obtidas para a operação da célula, utilizando oxigênio ou ar como oxidante

um melhor desempenho de polarização, quando comparada com a célula alimentada com $\mathrm{H}_{2}$ /ar como esperado. A diferença observada em toda a extensão da curva de polarização está relacionada não só ao uso de diferentes oxidantes (ar e $\left.\mathrm{O}_{2}\right)$, mas também às diferentes condições de operação utilizadas (temperatura e fluxo de gás).

$\mathrm{Na}$ célula operada com $\mathrm{H}_{2}$ /ar é observado um maior sobrepotencial por ativação (ver região ampliada da Figura $3 b$ ), que pode ser atribuído à menor pressão parcial de oxigênio presente no ar (21\%). Portanto, nesse tipo de célula o fluxo do gás oxidante usado se torna determinante. Por outro lado, além do aumento do fluxo, é necessário regular a pressão de saída dos gases para que seu valor seja suficientemente adequado, de modo a se obter um tempo de residência satisfatório dos reagentes nos sítios catalíticos.

Surpreendentemente, nas condições otimizadas em $0,7 \mathrm{~V}$, o desempenho da célula operando com $\mathrm{H}_{2} /$ ar foi apenas $20 \%$ menor do que a célula utilizando oxigênio como oxidante. Essa perda de $20 \%$ pode ser considerada reduzida, favorecendo a utilização de um gás mais abundante, seguro e de baixo custo. O resultado obtido é bastante promissor, demonstrando um avanço significativo no desenvolvimento da tecnologia de produção de GDLs, eletrodos e MEAs com grandes áreas geométricas destinados a módulos de potência de células PEMFC, no Brasil.

Na Figura 4 é mostrado o desempenho de dois MEAs, na ausência (eletrodo 1) e na presença da emulsão hidrofóbica (eletrodo 2). Observa-se claramente que o desempenho da célula na ausência da emulsão é menor em relação à curva obtida para o MEA, quando se utiliza a camada difusora modificada. A diferença de desempenho em relação à densidade de corrente para o potencial de $0,6 \mathrm{~V}$ é de $43 \%$. Como descrito anteriormente, o GDL tem um papel importante e fundamental na fabricação de EDGs, proporcionando uma melhora na distribuição dos gases, um maior controle sobre a hidrofobicidade e, consequentemente, um gerenciamento adequado de água na interface eletrodo/eletrólito, refletindo em um melhor desempenho geral da célula. 


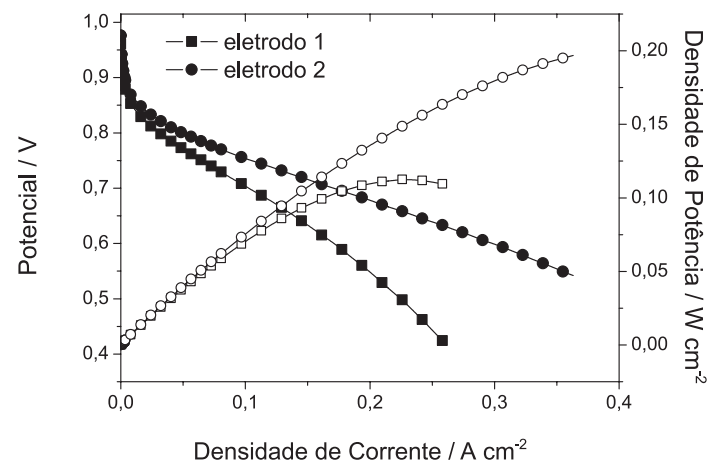

Figura 4. Curvas de polarização e potência para MEAs de área geométrica de $248 \mathrm{~cm}^{2}$ confeccionados na presença e na ausência de emulsão hidrofóbica, produzidos pelo método de impressão à tela

\section{CONCLUSÃO}

O grupo do CCCH/IPEN tem incentivado o desenvolvimento de componentes de células do tipo PEMFC, principalmente relacionados à produção de eletrodos e MEAs com áreas geométricas, de até 248 $\mathrm{cm}^{2}$, visando posterior comercialização pela indústria nacional. $\mathrm{O}$ método de impressão à tela utilizado na produção dos GDLs, bem como a adequação e o aumento de escala dos processos de produção de MEAs encontram-se praticamente desenvolvidos para a aplicação industrial, com bons desempenhos, demonstrando a viabilidade da comercialização desses MEAs em módulos de potência de células PEMFC com tecnologia $100 \%$ nacional.

\section{MATERIAL SUPLEMENTAR}

Disponível em http://quimicanova.sbq.org.br, na forma de arquivo PDF, com acesso livre. Na Figura 1S está apresentado um esquema ilustrativo de um MEA com os seus principais componentes. $\mathrm{Na}$ Figura 2Sa e b estão apresentadas as fotos ilustrativas dos equipamentos utilizados na confecção dos eletrodos e na preparação da Tinta Precursora da Camada Catalítica (TPCC), respectivamente. Ambos os equipamentos, o reator de preparação da TPCC e máquina de impressão, estão instalados no laboratório de confecção de MEAs do $\mathrm{CCCH}$ do IPEN.

\section{AGRADECIMENTOS}

Às agências de fomento FINEP (Financiadora de Estudos e Projetos) pelo apoio financeiro, processos $n^{\circ}$ 01.06.0918.00 e $n^{\circ}$ 01.06.0939.00, ao CNPq (Conselho Nacional de Desenvolvimento Científico e Tecnológico) e à FAPESP (Fundação de Amparo à Pesquisa do Estado de São Paulo - processo no 2009/10661-9) pelas bolsas concedidas. Os autores agradecem, também, à empresa Electrocell pela parceria no desenvolvimento da célula unitária e módulos.

\section{REFERÊNCIAS}

1. Linardi, M.; Economia e energia 2008, 66,15.

2. Wendt, H.; Götz, M.; Linardi, M.; Quim. Nova 2000, 23, 538.

3. Ticianeli, E. A.: Gonzalez, E. R.; Eletroquímica: Princípios e Aplicações, $6^{\mathrm{a}}$ ed., Edusp: Brasil, 2005.

4. Linardi, M.; Introdução à ciência e tecnologia de células a combustível, $1^{\text {a }}$ ed., ArtLiber: São Paulo, 2010.

5. Volumes dos Seminários bienais: Fuel Cell Seminars; por exemplo: Proc. Fuel Cell Seminar Orlando, Florida, USA, 1996; Courtesy Associates Inc.; Washington DC, 1996.

6. Volumes da Electrochimica Acta; por exemplo: Fuel Cells, 1998, 43.

7. Gierke, T. D.; Munn, G. E.; Wilson F. C.; J. Polym. Sci., Part B: Polym. Phys. 1981, 19, 1687.

8. Mauritz, K. A.; Moore, R. B.; Chem. Rev. 2004, 104, 4535.

9. EG\&G Technical Service, Inc.; Fuel Cell Handbook, U. S. Department of Energy: West Virginia, $7^{\text {th }}$ ed., 2004, cap. 3.

10. Wendt, H.; Linardi, M.; Aricó, E.; Quim. Nova 2002, 25, 470.

11. Ticianelli, E. A.; Camara, G. A.; Santos, L. G. R. A.; Quim. Nova 2005, 28, 664.

12. Andrade, A. B.; Dissertação de Mestrado, Universidade de São Paulo, Brasil, 2008.

13. Andrade, A. B.; Bejarano, M. L. M.; Cunha, E. F.; Robalinho, E.; Linardi, M.; J. Fuel Cell Sci. Technol. 2009, 6, 1.

14. Cunha, E. F.; Andrade, A. B.; Robalinho, E.; Bejarano, M. L. M.; Linardi, M.; Cekinski, E.; International Nuclear Atlantic Conference; Meeting on Nuclear Applications, $8^{\text {th }} /$ Meeting on Reactor Physics and Thermal Hydraulics, Santos, Brasil, 2007.

15. Cunha, E. F.; Andrade, A. B.; Robalinho, E.; Bejarano, M. L. M.; Cekinski, E.; Linardi, M.; Second European Fuel Cell Technology Applications Conference, Rome, Italy, 2007.

16. Robalinho, E.; Cunha, E. F.; Andrade, A. B.; Bejarano, M. L. M.; Linardi, M.; Cekinski, E.; Proceedings of the CONSOL Conference, Boston, USA, 2007.

17. Robalinho, E.; Tese de Doutorado, Universidade de São Paulo, Brasil, 2009.

18. Cunha, E. F.; Tese de Doutorado, Universidade de São Paulo, Brasil, 2009.

19. Bonifácio, R. N.; Dissertação de Mestrado, Universidade de São Paulo, Brasil, 2009.

20. Bonifácio, R. N.; Linardi, M.; Cuenca, R.; Quim. Nova 2011, 34, 96.

21. Bonifácio, R. N.; Paschoal, J. O. A.; Linardi, M.; J. Power Sources 2011, 196, 4680

22. Millington, B.; Du, S.; Pollet, B. G.; J. Power Sources 2011, 196, 9013.

23. Lin, J. F.; Wertz, J.; Ahmad, R.; Thommes, M.; Kannan, A. M.; Electrochim. Acta 2010, 55, 2746.

24. Ko, T. H.; Liao, Y. K.; Liu, C. H.; Energy Fuels 2008, 22, 4092.

25. Vielstich, W.; Gasteiger, H. A.; Lamm, A.; Handbook of Fuel Cells: Fundamentals, Technology and Applications, John Wiley and Sons, Ltd.: New York, 2003, vol. 3.

26. Lu, Z.; Daino, M. M.; Rath, C.; Kandlikar, S. G.; Int. J. Hydrogen Energy 2010, 35, 4222 . 